J. Lake Sci. (湖泊科学) , $2007, \mathbf{1 9}(5): 552-557$

http:// www. jlakes. org. E-mail: jlakes@ niglas. ac.cn

(C) 2007 by Journal of Lake Sciences

\title{
武汉月湖水生植被重建过程中浮游植物的动态变化”
}

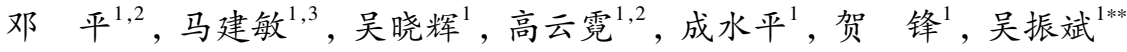 \\ ( $1:$ 中国科学院水生生物研究所淡水生态与生物技术国家重点实验室, 武汉 430072) \\ (2: 中国科学院研究生院, 北京 100049$)$ \\ (3:河南师范大学, 新乡 453002)
}

摘 要:2004 年 12 月 - 2005 年 5 月武汉市月湖水生植被重建过程中, 对浮游植物进行逐月调查. 结果表明, 在营养盐浓 度较高的条件下, 浮游植物仍保持较低的生物量和密度, 浮游植物的生长与温度保持一定的相关性, 但与湖水营养盐浓度 并不存在相关关系. 淔草和伊乐藻能使水体的透明度保持较高的状态. 浮游植物主要由隐藻和硅藻组成, 能形成水华的一 些常见种类并未随温度升高而出现, 可能与这两种沉水植物的存在改变了浮游植物的群落结构有关. 因此, 在水温较低的 冬季和春季进行水生植被重建是富营养化湖泊治理的有效途径.

关键词: 水生植被; 重建; 武汉月湖; 浮游植物

\section{Dynamics of phytoplankton in the process of the aquatic macrophyte rehabilitation in Lake Yuehu, Wuhan}

DENG Ping ${ }^{1,2}$, MA Jianmin ${ }^{1,3}$, WU Xiaohui ${ }^{1}$, GAO Yunni ${ }^{1,2}$, CHENG Shuiping ${ }^{1}$, HE Feng ${ }^{1}$ \& WU Zhenbin ${ }^{1}$ (1: State Key Lab. of Freshwater Ecology and Biotechnology, Institute of Hydrobiology, CAS, Wuhan 430072, P. R. China)

(2: Graduate School, Chinese Academy of Sciences, Beijing 100049, P. R. China)

(3: College of Life Sciences, Henan Normal University, Xinxiang 453002,P. R. China)

\begin{abstract}
From December, 2004 to May, 2005 phytoplankton was investigated monthly in the process of the aquatic vegetation rehabilitation in Lake Yuehu, Wuhan. The result indicated that, under the condition of high nutrition concentrations, phytoplankton was still maintained at low biomass and density; phytoplankton growth was positively correlated with the temperature, but not with nutrient concentrations. Potamogeton cripus and Elodea canadensis made water body maintain higher transparency. Phytoplankton was mainly composed of cryptophyta and diatom. The typical species of water bloom didn $t$ appear with the increase of temperature. The phytoplankton community structure was possibly changed by existence of these two submerged macrophytes. Therefore, rehabilitation of aquatic vegetation was the effective way to control the eutrophication of the lake in winter and spring of lower temperature.
\end{abstract}

Keywords: Aquatic macrophytes; rehabilitation; Lake Yuehu( Wuhan) ; phytoplankton

目前我国湖泊富营养化非常严重且呈恶化趋势 ${ }^{[1]}$. 富营养化导致水华的大量泛滥, 草型湖泊向藻型湖 泊转变. 湖泊治理的目标就是要实现藻型向草型的转变,构建比较良性的生态系统. 湖泊治理的基本措施主 要包括外源污染控制、内源污染控制和生态控制. 对于外源污染, 主要以截污为主 ${ }^{[2]}$; 对于内源污染,一般 采取疏浚底泥 ${ }^{[3]}$ 、覆盖底泥 ${ }^{[4]}$ 、固定营养盐 ${ }^{[5]}$ 等措施; 水生植被的恢复和重建是生态控制的主要手段, 国内

* 国家杰出青年基金项目 (39925007)、中国科学院知识创新工程重要方向项目 (KSCX2 - SW - 102) 及国家“十五” 重大科技专项 (2002AA601021) 联合资助. 2006-10-12 收稿;2006-12-13 收修改稿. 邓平,女,1979 年生,博士 生;E-mail:dengping2003@ ihb. ac. cn.

** 通讯作者;E-mail: wuzb@ihb. ac.cn. 
外已进行了一定的探索和研究 ${ }^{[6-8]}$. 菹草和伊乐藻是湖泊植被恢复中较常使用的沉水植物 ${ }^{[9,10]}$.

月湖位于武汉市汉阳城市中心, 约 $66.6 \times 10^{4} \mathrm{~m}^{2}$, 平均水深 $1.2 \mathrm{~m}$, 淤泥较深, 其中 $50 \%$ 以上的区域淤泥 超过 $1.5 \mathrm{~m}$, 其他区域 $0.3-1.5 \mathrm{~m}$. 目前的主要外源污染为生活污水. 湖水中氮、磷等营养盐丰富, 属劣 $\mathrm{V}$ 类. 本实验选择在月湖菹草生长至衰亡期间 (2004 年 12 月 - 2005 年 5 月) 研究浮游植物的动态变化, 期望 得到一些淔草和伊乐藻在治理富营养化湖泊过程中对浮游植物群落结构影响的资料.

\section{1 研究方法}

\section{1 水生植被重建}

菹草种群由月湖底泥种子库和 2004 年夏季播撒的菹草 (Potamogeton crispus L. ) 石芽发芽生长形成. 调 查阶段 (2004 年 12 月 - 2005 年 5 月) 前的 2004 年春夏季在月湖播撒了苦草(Vallisneria spiralis L. ) 种子并 种植了加拿大伊乐藻 (Elodea canadesis). 同时为了加强植物修复力度于 2005 年 1 月和 2 月各种植了 $10 \mathrm{t}$ 伊 乐藻, 4 月种植约 $160 \mathrm{~kg}$ 的黑藻 (Hydrilla verticillata) 冬芽并在全湖播撒了苦草种子. 2005 年 3 月和 5 月对水 草进行了两次大面积调查.

\section{2 水质监测}

根据月湖湖区特征,在全湖共设 8 个监测点(图 1). 于 2004 年 12 月 - 2005 年 5 月逐月对浮游植物的 种类组成、叶绿素 $\mathrm{a}$ 和主要水化学指标进行了同步监测. 浮游植物的采集和生物量的测定,按淡水浮游生物 研究方法 ${ }^{[11]}$ 进行; 水化学指标监测按《水和废水监测分析方法》 ${ }^{[12]}$ 进行. 其中 $2 、 5$ 和 6 号采样点一般情况 下每次必采,其他点采样频率较低.

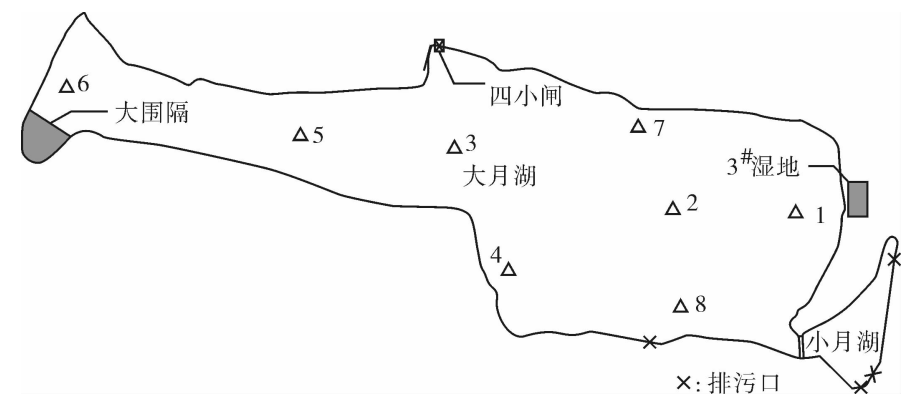

图 1 武汉月湖采样点示意图

Fig. 1 Sketch of sampling sites in Lake Yuehu, Wuhan

\section{2 结果与分析}

\section{1 水生植被的恢复}

2005 年 3 月 27 日对 2004 年冬季种植的植物成活和分布情况以及全湖的整体情况调查结果显示, 全湖 大型水生植物的总生物量约 $160 \mathrm{t}$, 总体覆盖度约 $15 \%$. 2005 年 5 月 14 日第 2 次全面调查结果显示, 植物的 扩展速度很快, 几乎全湖都有分布, 月湖大型植物总体覆盖度达到了 $45 \%$ 左右, 总生物量约为 $810.4 \mathrm{t}$ (表 1 ). 还有一个很重要的现象是, 自 5 月初开始, 紫萍大面积爆发, 调查时其盖度已经达到 $55 \%$ 左右, 在主体 湖区较多, 盖度可达 60\% 以上, 西部狭长区域较少, 约为 $20 \%-30 \%$, 其总生物量约有 $949 \mathrm{t}\left(2.74 \mathrm{~kg} / \mathrm{m}^{2}\right)$, 由于它的遮光等影响, 造成菹草大面积衰亡, 对伊乐藻也有明显影响.

调查期间月湖周围并未实现完全截污,每天仍有大量污水排人月湖.

\section{2 理化指标的变动}

2004 年 12 月 -2005 年 5 月期间温度和透明度 $(S D)$ 的变化情况显示, 水温逐渐升高, 但因 5 月出现短 期的温度降低, 使采样时的温度较 4 月低; 月湖前四个月都清澈见底, 只是由于水位的变化, SD 有所变化, 但 4 月 SD 明显降低,5 月提高 (图 $2 \mathrm{a}, \mathrm{b}$ ). 至于 $\mathrm{TN}$ 表现为在冬季逐渐升高,在春季降低,5 月又开始升高; TP 在冬季较低且差异很小, 春季开始快速增加 (图 2c,d). 
表 1 武汉月湖水生植被特征

Tab. 1 Characters of aquatic macrophytes in Lake Yuehu, Wuhan

\begin{tabular}{|c|c|c|c|c|c|c|}
\hline $\begin{array}{l}\text { 时间 } \\
\text { (年. 月. } \\
\text { 日 ) }\end{array}$ & $\begin{array}{l}\text { 大型 沉 } \\
\text { 水 植 物 } \\
\text { 盖度 }\end{array}$ & $\begin{array}{l}\text { 大型沉 水植 } \\
\text { 物生物量 (t) }\end{array}$ & $\begin{array}{l}\text { 沉水植物 } \\
\text { 优势种 }\end{array}$ & $\begin{array}{l}\text { 其他沉水植物 } \\
\text { 种类 }\end{array}$ & $\begin{array}{l}\text { 非沉水植物植 } \\
\text { 物 种 类 及 优 } \\
\text { 势种 }\end{array}$ & $\begin{array}{l}\text { 非沉水植物总 } \\
\text { 生物量 }(\mathrm{t})\end{array}$ \\
\hline $\begin{array}{l}2005 . \\
3.27\end{array}$ & $15 \%$ & 160 & 菹草 & $\begin{array}{l}\text { 伊乐藻, 金鱼 } \\
\text { 藻, 丝状藻 (很 } \\
\text { 多) }\end{array}$ & & \\
\hline $\begin{array}{l}2005 . \\
5.14\end{array}$ & $45 \%$ & 810.4 & 伊乐藻 & $\begin{array}{l}\text { 菹草 (很多), } \\
\text { 金鱼藻, 黑藻 }\end{array}$ & $\begin{array}{l}\text { 紫萍 (很多), } \\
\text { 荷花, 水鳖 }\end{array}$ & 949 \\
\hline
\end{tabular}
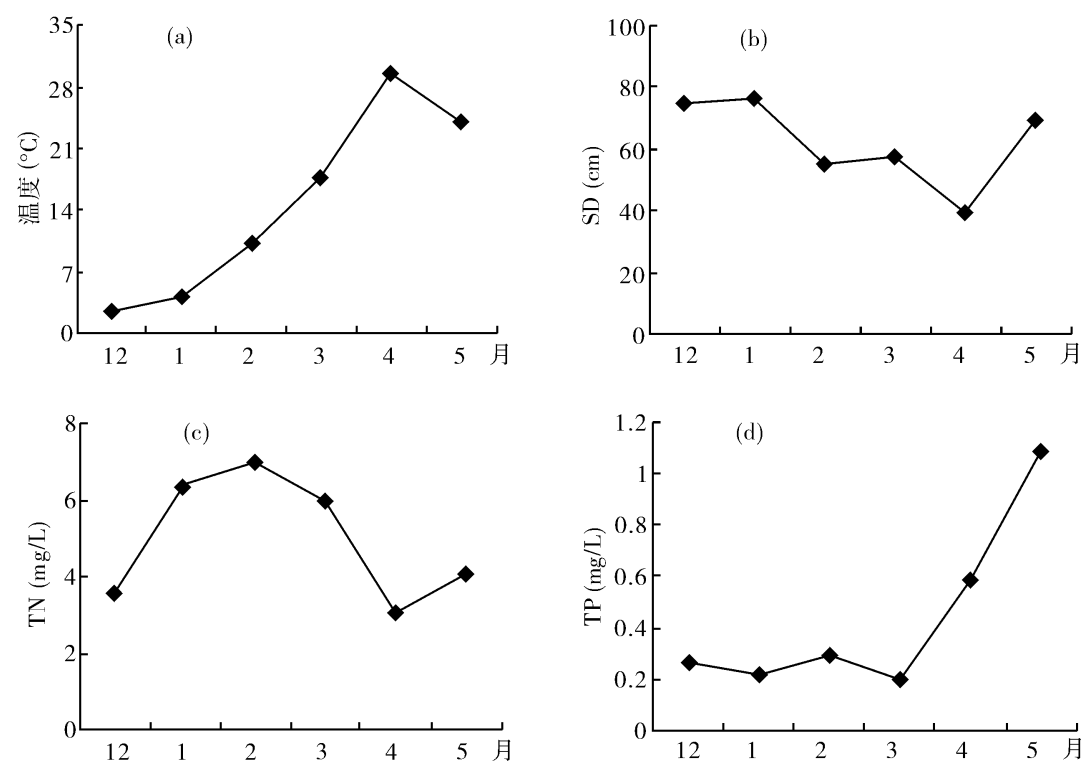

图 2 武汉月湖温度、SD、TN、和 $\mathrm{TP}$ 的变化

Fig. 2 Dynamics of temperature, SD, TN, and TP in Lake Yuehu, Wuhan

\section{3 浮游植物的种类组成和变化}

在研究期间,共检测出浮游植物 65 种,分属 7 门 45 属. 其中种类最多的是绿藻门,有 19 属 30 种, 占藻 类总数的 $46.15 \%$; 其次是硅藻门, 有 10 属 16 种, 占藻类总数的 $24.62 \%$; 蓝藻门 8 属 9 种, 占藻类总数的 $13.85 \%$; 裸藻门 3 属 5 种, 占藻类总数的 $7.69 \%$; 隐藻门 2 属 2 种, 占藻类总数的 $3.08 \%$; 甲藻门 2 属 2 种, 占藻类总数的 $3.08 \%$; 金藻门 1 属 1 种,且只在 1 月份 2 号采样点出现过一次.

调查期间蓝藻在月湖浮游植物生物量中所占的比重不高 (图 3a), 除 12 月和 1 月分别占到 $3.32 \%$ 和 $7.45 \%$, 其他几个月都非常低. 同样绿藻在调查期间占月湖浮游植物生物量的比重也不高, $12 、 2 、 4 、 5$ 这四 个月分别占到 $6.02 \% 、 6.70 \% 、 17.42 \%$ 和 $11.34 \%$, 其他两个月份非常少. 调查期间隐藻在月湖浮游植物生 物量中占较大的比重, $12 、 1$ 和 3 月以隐藻为主, 4 月以隐藻和硅藻为主, 5 月隐藻、裸藻和硅藻三门占生物 量的绝对优势. 硅藻还在 2 月占生物量中的优势.

就密度而言, $12 、 1$ 和 3 月以隐藻为主 (图 3b), 2 月硅藻、隐藻和绿藻为主, 4 月和 5 月硅藻、绿藻和蓝藻 为主. 蓝藻主要是细胞大小近 $2 \mu \mathrm{m}$ 的微小平列藻 (Merismopedia tenuissisma). 绿藻也是细胞个体较小的栅藻 
属 (Scenedesmus)、盘星藻属 (Pediastrum) 和纤维藻属 (Ankistrodesmus) 的种类. 硅藻主要是小环藻属 (Cyclotel$l a)$ 的种类. 隐藻主要是啮蚀隐藻 (Crypotomonas erosa). 裸藻主要是裸藻属 (Euglena) 和扁裸藻属 (Phacus) 的 种类. 甲藻数量很少, 主要是飞燕角甲藻 (Ceratium hirundinella) 和裸甲藻 (Gymnodinium aeruginosum).

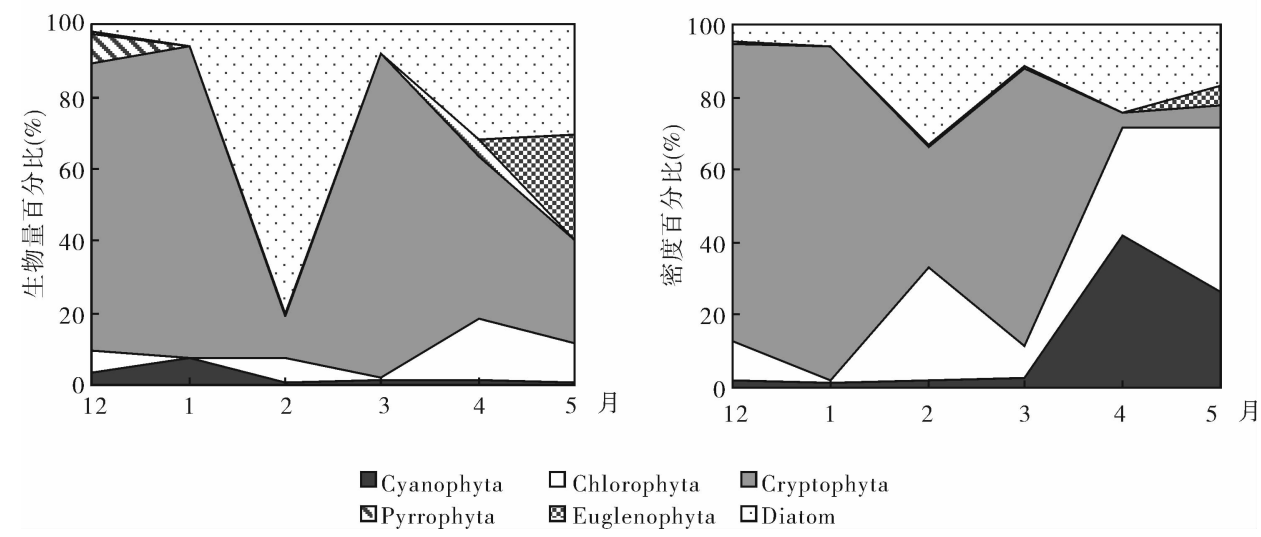

图 3 武汉月湖浮游植物生物量和密度组成的变化

Fig. 3 Changes of phytoplankton biomass and density compositions in Lake Yuehu, Wuhan

\section{4 浮游植物总量的变化及与环境因子的关系}

叶绿素 $\mathrm{a}$ 的量随时间的变化逐渐增加,但 5 月有明显的降低; 生物量在 2 月和 5 月有两次降低 (图 4a). 除 2 月外, 叶绿素 $\mathrm{a}$ 与生物量有较一致的变化. 浮游植物生物量和密度的变化表现出明显的季节性 (图 $4 \mathrm{~b}$ ). 冬季的生物量和密度明显低于春季, 12 月生物量和密度最低,而春季明显升高, 4 月达最高.
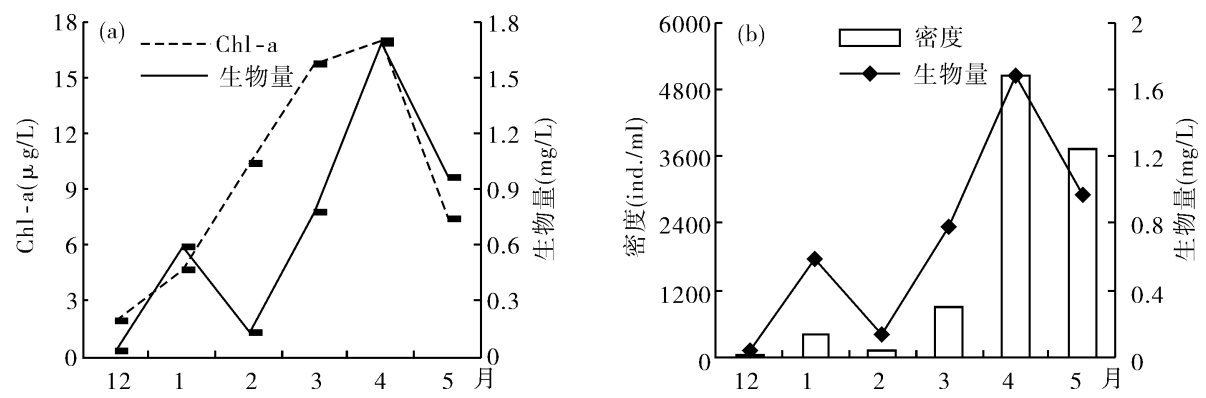

图 4 武汉月湖浮游植物生物量和叶绿素 $\mathrm{a}$ 的变化 (a) 以及浮游植物生物量和密度的变化关系 (b)

Fig. 4 Dynamics of phytoplankton biomass vs Chl-a content(a) and relations of phytoplankton biomass vs $\operatorname{density}(\mathrm{b})$ in Lake Yuehu, Wuhan

对 2004 年 12 月 - 2005 年 5 月这段时间内浮游植物生物量和几种理化因子之间的相关关系分析 (表 2) 可知, 月湖这段时期的浮游植物与 TN 和 TP 之间并不存在明显相关, 与温度则有一定的相关性.

\section{表 2 浮游植物生物量与理化因子的相关关系}

Tab. 2 Correlation between phytoplankton biomass and physical-chemical indices

\begin{tabular}{cccc}
\hline TN & TP & SD & 湿重 \\
\hline-0.49 & 0.50 & -0.66 & $0.88^{1)}$ \\
\hline
\end{tabular}




\section{3 讨论}

调查期间浮游植物生物量占优势的主要是隐藻和硅藻, 在 5 月份还出现了裸藻. 隐藻适应营养范围比 较广泛, 它们的存在与湖泊的营养状态无关 ${ }^{[13]}$, 而且在很多情况下其生物量可达 $80 \%$ 以上 ${ }^{[14]}$. 隐藻能在月 湖冬季和春季占据一定的优势, 与隐藻自身高的繁殖能力和对光照的要求比较低有关 ${ }^{[15]}$. 硅藻也是月湖冬 季和春季的主要类群, 优势种小环藻可在富营养化水体中形成优势种类. 湖体中主要藻类则由隐藻和硅藻 变为蓝藻和绿藻, 但增加的蓝藻和绿藻都是一些个体较小的种类, 形成水华的一些优势种类并未出现. 与水 生植被重建后相比, 未恢复水草前的 2004 年 3 月浮游植物虽然也是以隐藻占生物量和数量的绝对优势, 但 在 2 号采样点已出现了微囊藻群体.

冬季较高的透明度与前期水草的生长有关, 而较高的透明度又促进了蕰草和伊乐藻在冬季的生长 ${ }^{[26]}$. 在菹草生长阶段, 淔草 - 伊乐藻群落能明显减少富营养化水体中的 TN, 但对 TP 影响效果不明显. TP 值的 升高一方面可能与浮游植物生物量的增加促使底泥中磷的释放有关 ${ }^{[17]}$, 另一方面也与部分生活污水的排 人有关. 由于伊乐藻生长期较菹草长, 种植伊乐藻还能在一定程度上削减菹草死亡使水质恶化的后果 ${ }^{[18]}$. 在 5 月菹草衰亡阶段, 出现了一段降温天气, 再加上大量紫萍的出现, 浮游植物生物量也明显降低, 这也与 漂浮植物的出现对浮游植物产生一定的影响有关 ${ }^{[19]}$. 紫萍的大量出现也加速了菹草的衰亡和影响了伊乐 藻的生长, 可能会影响到后期的水质.

调查期间水体 TN 和 TP 浓度依然很高, 属于重富营养化水平, 而且透明度也很高, 水生植物的生长不 会构成对浮游植物的生长所需营养盐和光照的限制, 但浮游植物生物量和密度在这段时间均处于较低水 平. 以前也有湖泊营养盐浓度较高, 由于高等水生植物茂盛, 浮游植物生物量很少的研究报道 ${ }^{[20,21]}$. 本调查 中浮游植物生物量一方面表现出明显的季节相,相关性分析表明浮游植物与温度存在一定的相关性; 另一 方面浮游植物主要由隐藻和硅藻组成, 能形成水华的一些常见种类在菹草生长阶段并未出现, 可能与植物 的存在改变了浮游植物的群落结构有关. 有一些研究报道了水生植物可影响到浮游植物的群落结构 ${ }^{[22,23]}$.

在营养盐浓度较高的条件下, 由菹草和伊乐藻组成的水生植物群落可明显影响浮游植物的群落结构. 因此, 利用这两种沉水植物对冬季和春季富营养湖泊进行修复和重建有可能在较高的营养水平上实现湖泊 向大型植物占优势的清水状态转变.

致谢: 感谢何起立、张晟、吴娟、钟非和左进城等提供物理、化学指标方面的数据. 感谢梁威博士、张角元和刘 宝元老师对采样计划的制定. 感谢邓家齐老师对文章的修改.

\section{4 参考文献}

[1] 秦伯强,高 光, 胡维平等. 浅水湖泊生态系统恢复的理论与实践思考. 湖泊科学, 2005, 17 (1):9 $-16$.

[2] 朱季文,季子修,蒋自巽. 太湖湖滨带的生态建设. 湖泊科学, 2002,14(1): $77-82$.

[3] 菐培民,王国祥. 底泥疏浚能控制湖泊富营养化吗? 湖泊科学, 2000,12(3):269-279.

[4] Sttiben D, Walpersdof E. Application of lake marl at lake Arendsee, NE Germany first results of a geochemical monitoring during the restoration experiment. The Science of the Total Environment, 1998, 218: 33 -44 .

[5] Varjo E, Liikanen A. A new gypsum-based technique to reduce methane and phosphors release from sediments of eutrophied lakes: Gypsum treatment to reduce internal loading. Water Research, 2003, 37: $1-10$.

[6] Gulati R D. Can macrophytes be useful in biomanipulation of lakes? The lake Zwenmlust example. Hydrobiologia, 1990, 200/201: $399-407$.

[7] 李文朝. 浅型富营养湖泊的生态恢复——五里湖水生植被重建实验. 湖泊科学, 1996,8 (增刊): 1 -10 .

[8] 吴芝瑛, 吴 洁, 虞左明. 杭州西湖水生高等植物的恢复与水生生态修复. 环境污染与防治, 2005, 27 (1) $: 38-41$. 
[9] 吴玉树, 余国营. 根生沉水植物菹草 (Potamogeton crispus) 对滇池水体的净化作用. 环境科学学报, $1991, \mathbf{1 1}(4)$ : $411-416$.

[10］王国祥. 冬季水生高等植物对富营养化湖水地净化. 中国环境科学,1999,19(2): $106-109$.

[11] 章宗涉,黄祥飞. 淡水浮游生物研究方法. 北京:科学出版杜, 1991:333-344.

[12] 国家环境保护局编辑委员会. 水和废水监测分析方法. 第 3 版. 北京: 中国环境科学出版杜, 1989:246 -285 .

[13] Brettum P. Algae as indicators of water quality. Phytoplankton. Norsk Institut for vannforskning. 1989, NINA-Rapport 0 - 86116:1 - 111 (in Norwegian).

[14] Steward C A, Wetzel R G. Cryptophytes and other microflagellate as couplers in plankton community dynamics. Archive fur Hydrobiology, 1986, 106:1 - 19.

[15] 唐汇娟. 武汉东湖浮游植物生态学研究 [学位论文]. 中国科学院水生生物研究所, 2002:51.

[16] 水生高等植物一浮游植物关系和湖泊营养状态. 湖泊科学, 1998,10(4):83-86.

[17] 谢 平. 浅水湖泊内源磷负荷季节变化的生物驱动机制. 中国科学( D 辑),2005,35 (增刊 II ): $11-23$.

[18] 王文林,马 婷, 李 强等. 水生高等植物季相交替群落对富营养化水体净化效果调查. 环境监测管理 与技术, $2006, \mathbf{1 8}(1): 16-19$.

[19] 雷泽湘,徐德兰,黄沛生等. 太湖沉水和浮叶植被及其水环境效应研究. 生态环境, 2006,15(2):239 -243 .

[20] Mjelde M, Faafeng B. Ceratophyllum demersum (L. ) hampers phytoplankton development in some small Norwegian lakes over a wide range of phosphorus level and geographic latitude. Freshwater Biology, 1997, $37: 355-365$.

[21] 杨清心. 东太湖水生植被的生态功能及调节机制. 湖泊科学, 1998,10(1):67 - 72 .

[22] Jasser I. The influence of macrophytes on a phytoplankton community in experimental conditions. Hydrobiologia, 1995, 306: $21-32$.

[23] Schriver P, Bøestrand J, Jeppesen E et al. Impact of submerged macrophytes on fish-zooplanktonphytoplankton interactions: large-scale enclosure experiments in a shallow eutrophic lake. Freshwater Biology, 1995, 33 : $255-270$. 